\title{
ANÁLISE DE ALGUNS ASPECTOS MACROESTRUTURAIS DA DIREÇÃO PASSIVA DE DOIS DICIONÁRIOS BILÍNGUES ITALIANO-PORTUGUÊS / PORTUGUÊS-ITALIANO
}

Flávia Zanatta

Mestranda da UFRGS

RESUMO: O desenho de um dicionário bilíngue que almeja ser efetivamente eficiente para auxiliar no processo de ensino/aprendizagem de uma língua estrangeira, deve estar pautado em certas variáveis que condicionam o tipo de informações e a maneira como serão transmitidas ao consulente. Partindo da discussão acerca das variáveis direção, função, especificidades das línguas abordadas e público-alvo, analisamos alguns aspectos macroestruturais da direção passiva de dois dicionários bilíngues italiano-português/português-italiano - DRIP (2005) e MiDEI (2003) - no intuito de averiguar se as informações fornecidas aos usuários podem, de fato, auxiliá-los na aprendizagem da língua italiana. Os resultados obtidos nos possibilitam afirmar que ambos os dicionários podem ajudar, ainda que de maneira não plenamente satisfatória, um aprendiz de nível inicial na tarefa de decodificação do italiano.

PALAVRAS-CHAVE: lexicografia bilíngue, língua italiana, língua portuguesa, macroestrutura

ABSTRACT: The design of a bilingual dictionary that aims to assist effectively in teaching and learning a foreign language must be based on certain variables that affect the type of information and the way this piece of information will be presented to the user. Taking as a starting point the discussion about the variables direction, function, specificities of the languages included and target user, we analyze some macrostructural features of the passive direction of two dictionaries ItalianPortuguese/Portuguese-Italian - DRIP (2005) and MiDEI (2003) - in order to verify whether the information provided to the users may, in fact, help them in learning Italian. The results obtained allow us to state that both may help, although not in a completely satisfactory way, a beginning level learner in decoding texts in Italian.

KEYWORDS: bilingual lexicography, Italian, Portuguese, macrostructure

\section{Introdução}

De acordo com as propostas de classificação tipológica de obras lexicográficas apresentadas em Haensch (1982, p. 126-187), Martínez de Sousa (1995, s.v. diccionario), Landau (2001, p. 6-42), Hartmann; James (2001, s.v. typology), Swanepoel (2003) e Welker (2004, p. 35-54), o número de línguas configura um dos critérios empregados para definir e para distinguir as obras entre si. Tal critério permite que se opere uma separação entre os dicionários monolíngues e os dicionários multilíngues. Neste segundo grupo enquadra-se o dicionário bilíngue, definido por Hartmann; James (2001, s.v. bilingual dictionary) como "um tipo de dicionário que relaciona o vocabulário de duas línguas por meio de equivalentes” por Marello (1996, p. 31) como

um dicionário no qual as expressões de uma língua (chamada língua fonte ou de partida) são traduzidas para uma outra (chamada língua alvo ou língua de chegada). Mas não é somente a presença de duas línguas que faz de um dicionário um bilíngue. É a razão pela qual as duas línguas são postas em contato, isto é, a comunicação, pela tradução, entre duas comunidades que não compartilham a mesma língua ${ }^{[3]}$.

Para Marello (1996), a principal característica do dicionário bilíngue diz respeito à sua função de mediador da comunicação entre duas comunidades linguísticas. Landau (2001, p. 8) ressalta que o objetivo de um dicionário bilíngue é “oferecer ajuda para alguém que entende uma língua, mas não a outra”닐. Já Kromann; Riiber; Rosbach (1991, p. 2717, grifos no original) indicam que a função do dicionário bilíngue é "ser um auxílio para o tradutor ou na decodificação de um texto em língua estrangeira para um texto equivalente na língua nativa ou na codificação de um texto em língua nativa para um texto equivalente na língua 
estrangeira" empregados para desempenhar basicamente duas funções: auxiliar na compreensão ou na produção de textos.

Essas considerações evidenciam a existência de diversas questões envolvidas na concepção de obras lexicográficas bilíngues, conforme apontam os estudos metalexicográficos de Bugueño Miranda; Damin (2005), Welker (2004), Carvalho (2001) e Kromann; Riiber; Rosbach (1991). Bugueño Miranda; Damin (2005, p. 1), por exemplo, falam sobre a necessidade de se levar em conta pelo menos quatro variáveis quando da concepção e elaboração de um dicionário bilíngue, a saber: 1) a direção da obra, 2) a função da obra, 3) as especificidades das línguas abordadas e 4) o público ao qual a obra se destina.

Partindo das considerações precedentes, propomo-nos como objetivo para este trabalho analisar alguns aspectos macroestruturais de dois dicionários bilíngues para o par de línguas português e italiano, quais sejam: DRIP (2005) e MiDEI (2003). Nosso estudo centrar-se-á nas questões relativas à seleção macroestrutural quantitativa e qualitativa. Contudo, antes de partir à análise propriamente dita, faz-se necessário abordar detidamente cada uma das quatro variáveis que devem orientar o desenho de um dicionário bilíngue, posto que elas implicam diretamente a escolha e apresentação das informações a serem incluídas na obra e, consequentemente, na sua qualidade e eficácia.

\section{A direção e a função da obra}

O critério da direção está relacionado com a posição da língua materna do usuário da obra. Sabendo-se que os dicionários bilíngues apresentam relações entre a língua materna do usuário e uma língua estrangeira, deve-se observar se o dicionário opta por tomar a língua materna do usuário como língua-fonte (constituindo o lema) ou como língua-alvo (constituindo os equivalentes). Em função disso, as informações podem ser dispostas em duas direções: 1) da língua estrangeira (LE) para a língua materna (LM) e 2) da língua materna (LM) para a língua estrangeira (LE). No primeiro caso, fala-se em "direção passiva" e no segundo, em "direção ativa". Quando uma obra lexicográfica é composta por segmentos em ambas as direções (LEÒLM e LMÒLE), fala-se em dicionário bidirecional (cf. HARTMANN; JAMES (2001, s.v bidirectional dictionary) e LANDAU (2001, p. 9)). Segundo Marello (1996, p. 34), a bidirecionalidade de um dicionário bilíngue consiste na sua "aptidão para servir a duas comunidades linguísticas, seja como um dicionário de tradução [sc. passivo], seja como um dicionário de versão [sc. ativo]” ${ }^{, 6]}$. São, portanto, dicionários que podem ser utilizados pelos falantes nativos de ambas as línguas tratadas $\stackrel{[7]}{\text {. }}$

Com relação à função, deve-se atentar para o tipo de tarefa que o usuário almeja realizar com o auxílio do dicionário. Com base nesse critério, um dicionário pode ser pensado para a decodificação da língua estrangeira ou para a codificação em língua estrangeira ${ }^{[8]}$.

É fundamental ressaltar que o cruzamento dessas duas variáveis determina a existência de, pelo menos, quatro dicionários para cada par de línguas (cf. CARVALHO (2001, p. 52-53) e KROMANN; RIIBER; ROSBACH (1991, p. 2713-2716)). Como vimos, do ponto de vista da direção, uma mesma língua pode ser considerada língua-fonte ou língua-alvo e do ponto de vista da função, a obra pode ser cogitada para decodificação ou para codificação. Sendo assim, tomando como exemplo o par de línguas português e italiano, teríamos os seguintes tipos de dicionários:

1) Dicionários para falantes do português: 
Tipo A: italiano-português - português como língua-alvo - para decodificação - passivo

Tipo B: português-italiano - português como língua-fonte - para codificação - ativo

2) Dicionários para falantes do italiano:

Tipo A': português-italiano - italiano como língua-alvo - para decodificação - passivo

Tipo B': italiano-português - italiano como língua-fonte - para codificação - ativo

Cada uma das opções acima configura um dicionário monodirecional (cf. HARTMANN; JAMES (2001, s.v monodirectional dictionary) e LANDAU (2001, p. 9)) e monofuncional (cf. HARTMANN; JAMES (2001, s.v monofunctional dictionary)). Carvalho (2001, p. 53) assevera que esses quatro tipos de dicionários poderiam ser reduzidos a dois caso deixassem de ser monodirecionais e se convertessem em bidirecionais, podendo ser utilizados pelos falantes das duas línguas. Entretanto, para que o dicionário possa servir aos falantes de ambas as línguas, é preciso que supra satisfatoriamente suas diferentes necessidades, e esse é um projeto ainda de difícil execução, dada a complexidade da tarefa de congregar todas as informações necessárias para auxiliar os consulentes das duas línguas nos processos de decodificação e codificação simultaneamente.

Das considerações precedentes, concluímos que o perfeito entendimento das noções de direção e função do dicionário bilíngue é condição fundamental para a concepção dos componentes macroestrutural ${ }^{[9]}$ e microestrutural ${ }^{[10]}$ desse tipo de obra. Ambas as noções influenciam diretamente o tipo de informações que devem ser apresentadas, assim como se

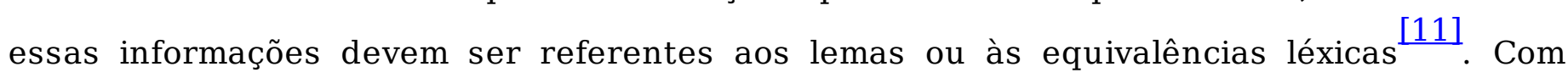
relação especificamente à função que o dicionário deve cumprir, é preciso ter claro suas implicações para a definição da macro- e da microestrutura. Um dicionário passivo deve ser macroestruturalmente denso e microestruturalmente conciso, posto que o usuário necessita sobretudo de informações no nível lexical. Em contrapartida, um dicionário ativo deve apresentar uma macroestrutura concisa e uma microestrutura densa, com uma grande quantidade de informações funcionais sobre os equivalentes, de modo a auxiliar o consulente no processo de codificação na língua estrangeira.

Do ponto de vista da variável "direção da obra", os dicionários que conformam nosso corpus de análise podem ser definidos como obras bidirecionais, posto que possuem dois segmentos (italiano-português e português-italiano). Quanto à variável "função da obra", constatamos que ambos os dicionários servem de auxílio para a realização tanto das tarefas de decodificação quanto de codificação.

\section{As especificidades das línguas abordadas}

Outro aspecto a ser levado em conta quando da concepção de um dicionário bilíngue diz respeito às especificidades das línguas abordadas, pois a obra deve estar equipada "para responder de forma efetiva a problemas resultantes da transposição realizada pelo usuário entre as línguas envolvidas" (cf. BUGUEÑO MIRANDA; DAMIN (2005, p. 4). Tais problemas decorrem do fato de não haver correspondência direta entre determinadas formas e estruturas de tais línguas. Em outras palavras, são frutos do anisomorfismo linguístico [12], fenômeno que se manifesta tanto entre línguas que divergem tipológica e geneticamente quanto entre línguas que apresentam semelhança tipológica e genética, como é o caso do português e do italiano, por exemplo. Pelo princípio do anisomorfismo linguístico, cada língua apresenta uma organização sui generis em cada um de seus níveis de organização (fonológico, morfológico, sintático, léxico, pragmático, etc.). Sendo assim, o dicionário deve dar conta de 
fenômenos que ocorrem nesses diversos níveis de estruturação da linguagem, tais como: a regência e a complementação verbal no nível sintático, os falsos amigos no nível léxico e a flexão verbal, de número e de gênero no nível morfológico. Enquanto aqueles fenômenos afetam unicamente a concepção da microestrutura do dicionário, estes afetam também a concepção da macroestrutura, no sentido de que a lematização de falsos amigos e de formas flexionadas é altamente recomendável em dicionários que põem em contraste duas línguas $[13]$.

\section{O público-alvo}

No tocante ao público-alvo, faz-se necessário definir a que grupo de falantes a obra se destinará. Um dicionário português-italiano, por exemplo, não pode ser o mesmo tanto para falantes nativos do português quanto para falantes nativos do italiano, pois as informações que cada público necessita são diferenciadas. Sendo assim, para que o dicionário possa ser uma ferramenta realmente eficaz, é preciso que sejam respeitadas as necessidades e as competências de cada público usuário ${ }^{[14]}$.

A delimitação precisa de um público-alvo, portanto, deve ser uma das primeiras decisões a serem tomadas pelo lexicógrafo quando da concepção de uma obra lexicográfica. Além da delimitação do público-alvo, é altamente recomendável que se trace um perfil de usuário para a obra. Assim, por exemplo, para um dicionário que trate do par de línguas português e italiano, pode-se definir como público-alvo os falantes nativos de português aprendizes de italiano ou os falantes nativos de italiano aprendizes de português. Porém, apenas essa distinção é muito abrangente. É imperativo que haja uma maior especificação com relação ao usuário. Tratando-se de aprendizes, por exemplo, é preciso levar em conta seu nível de conhecimento da língua estrangeira, a fim de que as informações fornecidas pelo dicionário satisfaçam as exigências específicas de cada nível. A questão do perfil de usuário dos dicionários, no entanto, é um tema ainda pouco abordado em lexicografia, gerando uma carência de estudos que sirvam para fundamentar a elaboração de obras a partir das necessidades do usuário a que se destinam ${ }^{[15]}$. Ao constatar essa carência de estudos, especificamente no âmbito da lexicografia bilíngue, Kromann; Riiber; Rosbach (1991, p. 2714) afirmam que

a questão do usuário é uma das áreas que realmente precisam ser examinadas mais detalhadamente - precisamos saber mais sobre o modo como as pessoas usam dicionários bilíngues e, especialmente, sobre sua competência linguística nas áreas da pronúncia, sintaxe, morfologia, semântica, estilo e seu conhecimento geral ou especializado da língua estrangeira e sua cultura ${ }^{[16]}$.

Landau (2001, p. 9), por exemplo, chama atenção para o fato de que "raramente um dicionário bilíngue identifica o usuário para quem ele é planejado” „17]. Em função disso, muitas vezes essas obras padecem de falhas gravíssimas, posto que deixam de apresentar informações altamente relevantes para o consulente ou apresentam informações completamente inócuas.

Com relação à variável "público-alvo", tanto DRIP (2005) quanto MiDEI (2003) são bastante genéricos. DRIP (2005, p. 5) destina-se “aos estudantes dos vários graus do ensino, bem como aos profissionais em geral, que têm de ter noções, e mesmo aprofundar o conhecimento da língua italiana". MiDEI (2003, p. VII) se destina aos "brasileiros que estudam a língua italiana e se preocupam em falar e escrevê-la corretamente". Além disso, a obra se apresenta aos estudantes como "um valioso instrumento para aperfeiçoar os 
conhecimentos da língua italiana” (cf. MiDEI (2003, p. VII). Com base nessa colocação, podese depreender que o dicionário se destina a um usuário que possui já algum conhecimento da língua italiana e que deseja "aperfeiçoá-lo". Já no caso de DRIP (2005), estamos diante de uma obra que pretende ser um auxílio tanto para estudantes e profissionais que não possuem nenhum conhecimento de língua italiana quanto para aqueles que já possuem e querem aprofundá-lo. A situação de DRIP (2005) é a mais problemática, posto que o dicionário pretende servir a diversos fins.

As situações anteriormente descritas permitem afirmar que apenas a definição do público a que se destina a obra não é suficiente para a elaboração de um dicionário bilíngue que seja efetivo para o desenvolvimento dos conhecimentos que venham a ser exigidos de um estudante brasileiro de língua italiana. Como já dissemos, para que seja possível determinar que tipo de informações serão incluídas no dicionário, é imperativo elaborar um perfil mais preciso do usuário da obra, definindo, por exemplo, seu nível de aprendizagem, pois é somente através dessa definição que o lexicógrafo poderá avaliar, a partir dos conteúdos fixados para o nível, quais serão as prováveis necessidades de consulta do estudante em questão. Concordamos, portanto, com Haensch (1982, p. 400) quando afirma que poderiam ser elaboradas obras lexicográficas muito mais úteis se as necessidades dos usuários fossem consideradas. Tais necessidades deveriam nortear a seleção e a apresentação das informações tanto na macroestrutura quanto na microestrutura do dicionário.

Na falta de um perfil de usuário claramente definido para DRIP (2005) e MiDEI (2003), consideramos pertinente trabalhar com uma concepção hipotética de usuário que nos permita elaborar parâmetros para a avaliação e constituição da macroestrutura da direção passiva dessas obras.

Um ponto de partida para a delineação de um perfil de usuário dessas obras seriam documentos oficiais que servem de orientação para o ensino da língua italiana. E essa operação metodológica é perfeitamente realizável, pois conta-se com o Quadro comune europeo di rifferimento per le lingue: apprendimento, insegnamento, vallutazione (Quadro comum europeu de referência para as línguas: aprendizagem, ensino, avaliação), doravante Quadro (2002), um documento no qual se encontram alguns parâmetros que norteiam o ensino da língua italiana ${ }^{[18]}$. No Quadro (2002) consta uma proposta para a classificação dos aprendizes de uma língua estrangeira de acordo com diferentes níveis de conhecimento, grau de competência que o aprendiz deve ter e as tarefas que deve ser capaz de realizar em cada nível. Partindo da tradicional divisão dos níveis de conhecimento de uma língua estrangeira em básico/elementar, intermediário e avançado, o Quadro (2002, p. 41-45) propõe uma classificação dos aprendizes em seis diferentes níveis, sendo que para cada um está prevista uma série de capacidades (competências) que os estudantes devem possuir para a realização de atividades de produção, recepção, interação e mediação, tanto na modalidade oral quanto na escrita, conforme descrevemos abaixo:

A1 ou "Contatto": nível mais baixo de conhecimento da língua que possibilita aos estudantes a realização de interações simples sobre temas específicos do cotidiano, dado que seu repertório léxico é bastante limitado;

A2 ou "Sopravvivenza": nível que permite aos estudantes realizar atos comunicativos de forma mais ativa, embora ainda possuam grandes limitações;

B1 ou "Soglia": nível de competência típica de viajantes, que possibilita uma interação mais flexível em situações ligada a problemas cotidianos;

B2 ou "Progresso": nível de competência que possibilita aos estudantes o uso da língua com fluidez e naturalidade;

C1 ou "Efficacia": nível de competência que possibilita aos estudantes a realização de 
tarefas complexas de trabalho e estudo e uma comunicação fluida e espontânea; C2 ou "Padronanza": é o maior nível de conhecimento da língua, que possibilita aos estudantes a capacidade se exprimir-se com espontaneidade, precisão e facilidade.

Partindo dessa classificação proposta pelo Quadro (2002) e baseados nas informações acerca do público-alvo presentes nos próprios dicionários sob análise, definimos como potenciais usuários dessas obras estudantes entre os níveis A1 ou "Contatto" e A2 ou "Sopravvivenza", ou seja, de nível inicial. Temos em mente, portanto, um dicionário passivo italiano-português para falantes brasileiros aprendizes de italiano em nível inicial.

Por fim, ainda que o Quadro (2002) não especifique detalhadamente quais os conteúdos que devem ser desenvolvidos em nível inicial, podemos afirmar que os usuários que se enquadram nesse nível necessitam de obras que ofereçam grande quantidade de informações sobre a língua estrangeira em nível léxico, para poder adquirir vocabulário e, principalmente, desempenhar-se sem maiores dificuldades nas tarefas de decodificação da língua que está sendo estudada.

Apresentadas todas essas considerações acerca das variáveis que têm implicação direta no desenho de um dicionário bilíngue, partiremos para a análise da macroestrutura de DRIP (2005) e MiDEI (2003). Reiteramos que restringiremos nossa análise do componente macroestrutural dessas obras à direção italiano-português, pois, como vimos, o desenho da macroestrutura é uma questão de maior relevância para a função de decodificação da língua estrangeira.

\section{Análise da macroestrutura da direção passiva de DRIP (2005) E MiDEI (2003)}

São relativas ao âmbito macroestrutural todas as questões relacionadas com a seleção e a ordenação do material léxico. Para Bugueño Miranda; Farias (2008, p. 137-138) a definição macroestrutural diz respeito ao estabelecimento do número de verbetes que o dicionário conterá, bem como do tipo de unidades léxicas passíveis de serem lematizadas. Ainda conforme esses autores, a definição do conjunto léxico a ser incluído no dicionário corresponde à definição macroestrutural quantitativa ${ }^{[19]}$. Além dessa, deve-se proceder a uma seleção macroestrutural qualitativa, a qual "permite elencar os tipos de unidades que podem fazer parte da macroestrutura” (cf. BUGUEÑO MIRANDA; FARIAS (2008, p. 138).

\subsection{A seleção macroestrutural quantitativa}

A seleção macroestrutural quantitativa depende diretamente da conjunção das variáveis função e público usuário ${ }^{[20]}$. Se a obra pretende auxiliar de maneira eficaz o consulente no processo de decodificação da língua estrangeira, é fundamental que o axioma básico da lexicografia bilíngue seja respeitado, ou seja, é preciso atentar para o fato de que um dicionário passivo deve ser macroestruturalmente denso e microestruturalmente conciso. Um usuário de nível inicial deve poder contar com um número significativo de palavrasentrada, posto que sua proficiência na língua estrangeira é muito baixa ou até mesmo nula. Béjoint (2002, p. 41-42), por exemplo, diz que a nominata de um dicionário bilíngue para compreensão deve ser extensa, incluindo "palavras raras, nomes próprios, todos os alomorfes de palavras, formas conjugadas exatamente da forma como são encontradas $[\ldots]^{,[21]}$.

Entretanto, a falta de estudos empíricos que permitam calcular a quantidade de 
vocabulário que um aprendiz de nível inicial precisa ter à sua disposição para poder desempenhar com sucesso a atividade de decodificação da língua estrangeira impede que se possa definir com precisão a densidade macroestrutural de um dicionário passivo de italiano para estudantes brasileiros. Sabe-se, no entanto, que as necessidades previstas para o nível do usuário a que a obra se destina devem ser levadas em conta.

A seguir, apresentamos alguns critérios que podem ser aplicados à definição macroestrutural quantitativa de um dicionário bilíngue.

\subsubsection{Critérios para a seleção macroestrutural quantitativa}

Bugueño Miranda (2005, p. 21-22) e (2007a, p. 265-266) cita dois critérios que podem ser empregados para se efetuar a seleção macroestrutural quantitativa dos dicionários gerais de língua e que podem ser perfeitamente aplicáveis aos dicionários bilíngues: 1) o critério estatístico e 2) o(s) critério(s) sin- ou (dis)sistêmico(s).

O critério estatístico se baseia na representação estatística do léxico, através da qual se estabelece uma escala de frequência de palavras e calcula-se um número mínimo de ocorrências. Caso a frequência de uma unidade for menor que o número mínimo de ocorrências, essa unidade não fará parte da macroestrutura do dicionário. No entanto, consideramos que existe uma premissa básica para a aplicação desse critério: é preciso trabalhar com corpus $[22]$.

$\mathrm{O}(\mathrm{s})$ critério(s) sin- ou (dia)sistêmico(s) dizem respeito à lematização ou não de vocabulário marcado e toma como base a concepção diassistêmica da linguagem proposta por Eugenio Coseriu (cf. COSERIU (1980a), (1980b) e (1980c)). De acordo com essa concepção, uma língua apresenta variação interna em eixos, como a diacronia (variação no tempo), a diatopia (variação no espaço geográfico), a diafasia (variação de acordo com os níveis de fala) e a diastratia (variação de acordo com os estratos sócio-culturais) ${ }^{[23]}$. Esses critérios, associados à definição de um perfil de usuário, possibilitam a elaboração de parâmetros que justifiquem a inclusão ou exclusão de certas unidades léxicas no dicionário e a observância a tais critérios poderá garantir que as expectativas do estudante de uma língua estrangeira sejam atendidas, pois lhe será disponibilizada uma quantidade de material léxico que de fato poderá ser aproveitada.

\subsubsection{Sincronia versus diacronia}

Com relação ao eixo diacrônico, acreditamos que um dicionário bilíngue deva adotar uma perspectiva sincrônica, posto que o aprendiz deve ter contato com a língua que seja efetivamente empregada pelos falantes nativos da língua estrangeira. Logo, não deveriam constar na macroestrutura unidades léxicas de baixa frequência, antiquadas ou desusadas. A fim de averiguar se DRIP (2005) e MiDEI (2003) lematizam vocabulário marcado diacronicamente, fizemos, através da ferramenta de busca Google ${ }^{[24]}$, uma análise da frequência de uso das unidades léxicas arroladas em um intervalo lemático da letra "C"

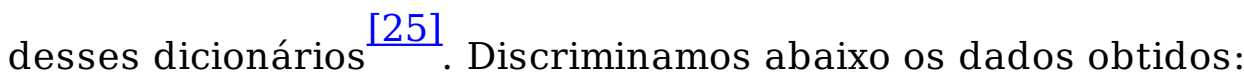

Quadro 1: dados da frequência de uso de um intervalo lemático da letra "C"

\begin{tabular}{|c|c|}
\hline DICIONÁRIOS & NÚMERO DE \\
& OCORRÊNCIAS \\
\hline
\end{tabular}




\begin{tabular}{|c|c|c|c|}
\hline $\begin{array}{c}\text { DRIP } \\
\mathbf{( 2 0 0 5 )}\end{array}$ & $\begin{array}{c}\text { MiDEI } \\
\mathbf{( 2 0 0 3 )}\end{array}$ & $\begin{array}{c}\text { número total } \\
\text { de } \\
\text { ocorrências } \\
\text { no Google }\end{array}$ & $\begin{array}{c}\text { número de } \\
\text { ocorrências } \\
\text { não } \\
\text { repetidas }\end{array}$ \\
\hline \multicolumn{3}{|c|}{ Intervalo lemático da letra “C” } \\
\hline ciera & - & 42.600 & 680 \\
\hline cifra & cifra & 5.740 .000 & 717 \\
\hline cifrare & cifrare & 47.800 & 721 \\
\hline cifrario & - & 25.100 & 684 \\
\hline ciglio & ciglio & 493.000 & 754 \\
\hline cignale & - & 29.000 & 751 \\
\hline cigno & cigno & 640.000 & 821 \\
\hline cigolare & cigolare & 62.300 & 804 \\
\hline- & cigolio & 43.300 & 752 \\
\hline ciliegia & ciliegia & 366.000 & 774 \\
\hline ciliegio & ciliegio & 566.000 & 766 \\
\hline cilindrico & cilindrico & 386.000 & 811 \\
\hline cilindro & cilindro & 3.010 .000 & 715 \\
\hline cima & cima & 8.080 .000 & 739 \\
\hline cimare & cimare & 8.080 & 657 \\
\hline cimalo & cimbalo & 14.500 & 741 \\
\hline cimentare & cimentare & 3.390 .000 & 791 \\
\hline cimento & cimento & 657.000 & 734 \\
\hline cimice & cimice & 63.800 & 754 \\
\hline ciminiera & ciminiera & 75.700 & 807 \\
\hline cimitero & cimitero & 1.700 .000 & 809 \\
\hline- & cinciglia & 28 & 28 \\
\hline cincischiare & cincischiare & 13.200 & 796 \\
\hline & & & \\
\hline & & & \\
\hline
\end{tabular}

Essa breve análise nos mostrou que tanto DRIP (2005) quanto MiDEI (2003) privilegiam a sincronia. Excetuando-se o vocábulo cinciglia, presente apenas em MiDEI (2003), que apresenta um baixo número de ocorrências, consideramos que as demais unidades léxicas foram acertadamente incluídas na macroestrutura.

\subsubsection{Diatopia, diafasia e diastratia}

Com relação ao vocabulário com marcação diatópica e diafásico-diastrática, Bugueño Miranda (2005, p. 21) ressalta que, para se proceder à sua inclusão, é preciso contar com instrumentos confiáveis de coleta e análise de dados. Carvalho $(2001$, p. 69) defende a inclusão de variantes diatópicas em dicionários passivos por serem desconhecidas pelos usuários e por considerar que um grande número de variantes lematizadas será de grande valia para o consulente. O mesmo poderia ser aplicado no caso do vocabulário que leva marcas diafásico-distráticas.

No caso do italiano, a variação diatópica é mais notada no nível fonético-fonológico. Segundo LoDuca (2002, p. 8), as diversidades regionais do italiano se fazem notar sobretudo no nível da pronúncia. É claro que há variação também nos níveis léxico, morfológico e sintático. Porém, em se tratando da elaboração de materiais de cunho normativo, como o são os dicionários, essas variações são suplantadas pela variedade padrão da língua. Com base nisso, consideramos que um dicionário bilíngue italiano-português para iniciantes deva aterse apenas a essa variedade da língua italiana. MiDEI (2003) parece seguir essa indicação ao afirmar que o dicionário se destina àqueles estudantes de língua italiana que "se preocupam em falar e escrevê-la corretamente" (cf. MiDEI (2003, p. VII)), ou seja, de acordo com a variedade padrão. Fato é que não encontramos vocabulário marcado diatopicamente nesse dicionário nem tampouco em DRIP (2005). 
Quanto ao vocabulário possuidor de marcação diafásico-diastrática, somos partidários de que um dicionário para iniciantes deva incluí-lo sempre e quando tiver amplo uso. Além disso, é imperativo que a obra forneça ao usuário a informação de que tais vocábulos não são neutros, em outras palavras, não fazem parte do conjunto léxico que não se encontra marcado no diassistema. Nesse sentido, MiDEI (2003) se mostra menos deficitário que DRIP (2005). Enquanto aquele apresenta marcação diafásico-diastrática em uma grande quantidade de verbetes (cf., por exemplo, MiDEI (2003), s.v. cacaiola, chiacchierio, chiappa, ciurma, spifferare, vasellame), aquele, apesar de lematizar vocábulos não neutros, tais como cacca, chiacchierata, orinale e sedere (DRIP (2005, s.v.)), apresenta marcação em poucos (cf. DRIP (2005), s.v. pisciare, pisciata, puttanaio, scoreggia). Vale ressaltar que essas marcas, diferentemente daquilo que ocorre em praticamente todas as obras lexicográficas, aparecem ao final do verbete, entre parênteses, como ilustramos a seguir: pisciare (...) v.t. urinar, mijar (vulgar) (DRIP (2005, s.v.)); scoreggia (...) s.f. peido (vulgar) (DRIP (2005, s.v.)).

\subsubsection{A repetição desnecessária de informações: um problema que afeta a densidade macroestrutural}

Evidenciamos em ambas as obras um comportamento que afeta diretamente a densidade macroestrutural e que consideramos decorrente de uma falta de otimização das informações oferecidas nos anexos que constam nos dicionários.

Tanto DRIP (2005) quanto MiDEI (2003) fornecem ao consulente ao final da obra, no Back Matter ${ }^{[27]}$, um conjunto de listas contendo informações de diferente natureza. MiDEI (2003) traz uma lista contendo os numerais ordinais e cardinais e outra contendo os adjetivos pátrios relativos a regiões e cidades da Itália. DRIP (2005) também traz uma lista contendo os numerais ordinais e cardinais e outras quatro, contendo os dias da semana, os meses, as estações e as cores. A presença dessas listas dispensaria a lematização dos vocábulos que abarcam, excetuando-se, obviamente, os casos em que o vocábulo possui mais de uma significação ou faz parte de fraseologias de significação não-transparente (cf., por exemplo, MiDEI (2003), s.v. giallo, ottocento, novecento, rosso)). Bastaria que fosse informado ao

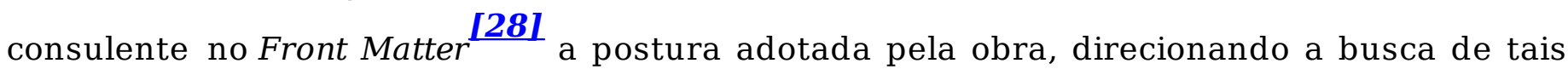
informações para o Back Matter ${ }^{[29]}$. Entretanto, ambos lematizam algumas dessas unidades, repetindo desnecessariamente um conjunto de vocábulos os quais ocupam um espaço que poderia ser dedicado a outras informações. Para nós, esse comportamento demonstra que a inclusão de listas está mais ligada a uma práxis lexicográfica de fornecer apêndices contendo informações gramaticais, geralmente referentes à conjugação verbal, sem maiores preocupações com sua real funcionalidade.

\subsection{A seleção macroestrutural qualitativa}

A seleção macroestrutural qualitativa diz respeito ao tipo de unidades léxicas passíveis de serem lematizadas. De um modo geral, os dicionários costumam apresentar um conjunto bastante heterogêneo de elementos lematizados, tais como lexemas plenos simples, lexemas plenos compostos, afixos, siglas, abreviaturas, unidades plurilexemáticas. Para nossa análise, abordaremos apenas os lexemas plenos simples.

Bugueño Miranda (2007a, p. 266) divide os lexemas pleno simples em comuns e próprios. Estes podem ser subdivididos em antropônimos e topônimos. Já aqueles devem ser avaliados a partir da distinção entre type (forma canônica) e token (forma variante) ${ }^{[30]}$. Essa 
distinção se manifesta em dois aspectos: 1) na lematização de formas variantes e 2) na lematização de formas flexionadas.

\subsubsection{Lexemas plenos simples próprios}

É muito comum os nomes próprios (antropônimos) e os nomes geográficos (topônimos) variarem de uma língua para outra. Quando duas línguas são postas em contraste, essas questões devem ser consideradas, sobretudo em se tratando de um dicionário para aprendizes de nível inicial, dado seu pouco conhecimento da língua estrangeira. Não há, no entanto, consenso quanto à lematização desse tipo de unidades léxicas. Welker (2004, p. 97) preconiza que somente os nomes das personalidades e dos lugares mais importantes devem ser registrados no dicionário. Além disso, esse autor defende que o critério para a inclusão dessas unidades é a frequência de uso (cf. Welker (2004, p. 209)). Bugueño Miranda (2007a, p. 267-268) aventa a possibilidade de se lematizar nomes próprios sempre que possuírem um valor lexicográfico, a exemplo de Bauhaus "diz-se daquilo que é feito no estilo da escola de arquitetura e artes decorativas Bauhaus" (cf. HouE (2001, s.v.)) e de Winchester "carabina americana de repetição, usada nas guerras de Secessão e de 1870” (cf. HouE (2001, s.v.)). Carvalho (2001, p. 68), por sua vez, considera de maior relevância a lematização de nomes geográficos.

Não temos dúvidas de que a presença dessas unidades em um dicionário bilíngue para iniciantes é de grande relevância, porém a forma como serão apresentadas vai depender da opção do lexicógrafo, que pode decidir por sua lematização ou por apresentá-las em apêndices no Back Matter.

Nos dicionários analisados não encontramos lematizados antropônimos. Tampouco aparecem topônimos na macroestrutura dessas obras. Em MiDEI (2003) podemos encontrar topônimos relativos exclusivamente às regiões da Itália no Back Matter, na lista de adjetivos pátrios fornecida pela obra. Entretanto, não há nenhuma indicação ao consulente de que a obra fornece essas informações. Nesse aspecto, consideramos que ambos os dicionários são deficitários, pois a inclusão de topônimos como Firenze, Milano, Svezia, Norvegia, Svizzera, Mosca, seja na macroestrutura, seja em uma lista onomástica, é altamente relevante para um estudante brasileiro de nível inicial.

\subsubsection{Lexemas plenos simples comuns}

Os lexemas plenos simples comuns conformam a maior parte da macroestrutura de uma obra lexicográfica. Em dicionários bilíngues, deve-se atentar para a lematização de formas variantes e, sobretudo, para a lematização de formas flexionadas, pois estas representam uma real dificuldade para o estudante de uma língua estrangeira de nível inicial.

\subsubsection{Lematização de formas variantes}

A lematização de formas variantes é fundamental em dicionários bilíngues, posto que o consulente pode recorrer ao dicionário em busca de informações, sobretudo relativas à significação, tanto a partir da forma type (canônica) quanto a partir da forma token (variante). A inclusão de formas variantes, contudo, deve obedecer a certas condições. Todas as formas variantes que forem desusadas e até mesmo as que possuam baixa frequência de uso não devem ser registradas no dicionário. Também se deve evitar a lematização de formas token marcadas diatópica e diafásico-diastraticamente.

Cumpridas essas exigências, ambas as formas são passíveis de fazer parte da 
macroestrutura. Quando isso ocorre, geralmente uma das formas é apontada como de uso preferencial, e essa informação deve ser transmitida ao consulente. O mecanismo mais comumente empregado para alertar o consulente sobre essa situação consiste na utilização de um sistema de remissões. Ambas as formas são lematizadas, cada qual no lugar que lhes cabe, respeitando a progressão alfabética, porém na forma token é fornecida apenas uma remissão para a forma type, a qual se apresenta como verbete completo. MiDEI (2003) se vale desse mecanismo. Encontramos diversos casos de variantes, tais como: mangiabile/mangereccio, nemmeno/nemmanco, nessuno/niuno, tram/tranvai e uovo/ovo. As formas que aparecem primeiro no sistema de barras são as apontadas pela obra como type, enquanto as que aparecem em segundo são as formas de token. Em DRIP (2005) encontramos lematizados os vocábulos nemmeno, nemmanco, tram, tranvai, uovo e ovo, porém não há indicação de que são formas variantes.

Dado o comportamento divergente dos dois dicionários, recorremos a uma obra monolíngue (DIo (2009)) para obtermos maiores informações acerca da situação de tais vocábulos. Apresentamos no quadro abaixo as informações levantadas:

Quadro 2: Situação das variantes ortográficas em DRIP (2005), MiDEI (2003) e DIo (2009)

\begin{tabular}{|c|c|c|c|c|c|}
\hline \multicolumn{2}{|c|}{ DRIP (2005) } & \multicolumn{2}{c|}{ MiDEI (2003) } & \multicolumn{2}{c|}{ DIo (2009) } \\
\hline type & token & type & token & type & token \\
\hline mangiabile & - & mangiabile & mangereccio & $\begin{array}{c}\text { mangiabile } \\
\text { mangereccio }\end{array}$ & \\
\hline $\begin{array}{c}\text { nemmeno } \\
\text { nemmanco }\end{array}$ & & nemmeno & nemmanco & nemmeno & nemmanco \\
\hline nessuno & - & nessuno & niuno & nessuno & niuno \\
\hline tram & - & tram & tranvai & tram & tranvai \\
\hline $\begin{array}{c}\text { uovo } \\
\text { ovo }\end{array}$ & & uovo & ovo & uovo & ovo \\
\hline
\end{tabular}

Observe-se que DIo (2009) considera as formas mangiabile e mangereccio como type. É um indício de que ambas são igualmente legitimadas na língua. Uma pesquisa no Google nos mostrou que a forma mangiabile possui 17.700 ocorrências enquanto a forma mangereccio possui 13.800 .

Quanto aos pares nemmeno/nemmanco e nessuno/niuno, encontramos em DIo (2009) a informação de que as formas nemmanco e niuno são arcaicas, condição para sua exclusão da macroestrutura de DRIP (2005) e MiDEI (2003). Os dados referentes à frequência de uso obtidas através do Google evidenciam 9.380.000 ocorrências para nemmeno e 27.500 para nemmanco e 21.600.000 ocorrências para nessuno enquanto que a forma niuno ocorreu 313.000. Ainda que os vocábulos nemmanco e niuno tenham uma frequência de uso expressiva, se comparamos com o número de ocorrências das formas nemmeno e nessumo vemos que há uma diferença bastante alta, o que pode servir como indício de que essas unidades estão em processo de desuso. Para os demais casos, DIo (2009) evidencia claros casos de type e token. Os dados de frequência corroboram essa informação: são 1.190.000 ocorrências para tram frente a 20.100 para tranvai. Da mesma forma, encontramos 1.650.000 ocorrências pra uovo e 599.000 para ovo.

Essas informações nos permitem afirmar que tanto DRIP (2005) quanto MiDEI (2003) são problemáticos no que concerne à lematização de formas variantes. Ambos lematizam, por

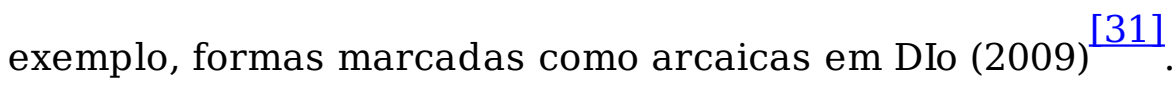

\subsubsection{Lematização de formas flexionadas}


A lematização de formas flexionadas é um problema ligado especialmente ao registro de tokens no dicionário. Em lexicografia, o procedimento mais empregado é a lematização da forma canônica dos vocábulos, ou seja, a forma infinitiva de verbos, masculino singular para substantivos, pronomes possessivos e demonstrativos, por exemplo. Entretanto, há um consenso de que em dicionários voltados para o ensino/aprendizagem de uma língua estrangeira, como os learner's dictionaries e os dicionários bilíngues, deve-se lematizar também formas flexionadas $\stackrel{[32]}{ }$, pois o aprendiz, sobretudo de nível inicial, não tem conhecimento suficiente da língua para saber que, por exemplo, a palavra italiana vissuto é o particípio passado do verbo vivere.

Os dicionários analisados, entretanto, não lematizam formas verbais flexionadas. É

oferecida apenas a conjugação de alguns verbos regulares e irregulares no Back Matter ${ }^{[33] .}$ As únicas formas flexionadas que encontramos tanto em DRIP (2005) quanto em MiDEI (2003) se referem aos pronomes possessivos e demonstrativos, o que consideramos uma decisão acertada, pois dessa forma o dicionário contempla as particularidades da morfologia flexional da língua italiana. Assim, o consulente encontra na macroestrutura dessas obras as formas mie, miei, nostre, nostri, quei, quegli, quelle, quelli, quello, queste, questi, vostre, vostri. MiDEI (2003) ainda traz quadros explicativos após alguns desses verbetes, nos quais informa ao consulente sobre o emprego dessas unidades.

\section{Conclusão}

Nosso propósito neste trabalho foi avaliar alguns aspectos referentes à seleção macroestrutural quantitativa e qualitativa de dois dicionários bilíngues italianoportuguês/português-italiano. Para tal, iniciamos expondo os parâmetros básicos que devem nortear a concepção de qualquer obra lexicográfica bilíngue: a direção e a função da obra, as especificidades das línguas abordadas e o público-alvo. Com relação a este último parâmetro, consideramos pertinente esboçar um perfil de usuário brasileiro para um dicionário passivo italiano-português, dado que as obras analisadas se destinam aos diversos potenciais usuários. Por fim, tomando por base a discussão realizada, passamos à análise da macroestrutura da direção passiva (italiano-português) de DRIP (2005) e MiDEI (2003) buscando averiguar se o conjunto léxico que conforma a macroestrutura dessas obras é realmente apropriado para um aprendiz de nível inicial e eficaz no processo de aprendizagem da língua italiana.

Os resultados obtidos através da análise efetuada nos possibilitam afirmar que ambas as obras, ainda que de maneira bastante precária, podem auxiliar um aprendiz de nível inicial na tarefa de decodificação da língua italiana. Destacamos que a precariedade dessas obras se deve, principalmente, aos seguintes fatores: 1) lematização de unidades léxicas cuja frequência de uso é insignificante ou até mesmo nula, 2) repetição desnecessária de informações na macroestrutura, 3) falta de critérios para o tratamento das formas variantes e 4) não-lematização de formas verbais flexionadas.

Dentre os dois dicionários analisados, DRIP (2005) é o que apresenta mais problemas com relação ao estabelecimento da macroestrutura. Entretanto, consideramos que ambas as obras precisariam sofrer uma reformulação da macroestrutura da direção passiva para que pudessem ser convertidas em ferramentas realmente eficazes para os aprendizes da língua italiana de nível inicial.

\section{Referências}


BÉJOINT, H. Towards a bilingual dictionary for "comprehension". In: FERRARIO, H.; PULCINI, V. La lessicografia bilingue tra presente e avvenire. Vercelli: Mercurio, 2002, p. 33-48.

BERBER SARDINHA, T. Lingüística de Corpus. São Paulo: Manole, 2004.

BUGUEÑO MIRANDA, F. V. O que o professor deve saber sobre a nominata do dicionário de língua. Revista Língua \& Literatura, Frederico Westphalen, v.6/7, n. 10/11, 2005, p.17-31.

. O que é macroestrutura no dicionário de língua? In: ALVES, Ieda Maria, ISQUERDO, Aparecida Negri (Org.). As ciências do léxico III. São Paulo, Campo Grande: Humanitas, Editora UFMS, 2007a, p. 261-272.

. A definição do perfil de usuário e a função da obra lexicográfica em um dicionário de aprendizes. Expressão, Santa Maria, n.2, jul./dez. 2007b, p. 89-101.

BUGUEÑO MIRANDA, F. V.; DAMIM, C. P. Elementos para uma escolha fundamentada de dicionários bilíngües português/inglês. Entrelinhas, São Leopoldo, v. 2, n. 3, 2005, p. 1-10.

BUGUEÑO MIRANDA, F. V.; FARIAS, V. S. Desenho da macroestrutura de um dicionário escolar de língua portuguesa. In: Cláudia Xatara; Cleci Bevilacqua; Philippe Humblé. (Org.). Lexicografia Pedagógica: Pesquisas e Perspectivas. Florianópolis: UFSC/NUT, v. 1, 2008, p. 129167.

CARVALHO, Orlene Lúcia de Sabóia. Lexicografia bilíngüe português/alemão: Teoria e aplicação à categoria das preposições. Brasília: Thesaurus, 2001.

CELD (2004). Collins Cobuild Compact English Learner's Dictionary. São Paulo: Disal, 2004.

COSERIU, E. Criatividade e técnica lingüística: os três níveis da linguagem. In: COSERIU, E. Lições de Lingüística Geral. Rio de Janeiro: Ao Livro Técnico, 1980a, p. 91-100.

. A língua funcional. In: COSERIU, E. Lições de Lingüística Geral. Rio de Janeiro: Ao Livro Técnico, 1980b, p. 101-117.

. Sistema, norma e falar concreto. In: COSERIU, E. Lições de Lingüística Geral. Rio de Janeiro: Ao Livro Técnico, 1980c, p. 119-125.

DAMIN, C. P. Parâmetros para uma avaliação do dicionário escolar. 2005. 230 f. Dissertação (Mestrado em Letras) - Instituto de Letras, Universidade Federal do Rio Grande do Sul, Porto Alegre, 2005.

DIo (2009). Dizionario Italiano online. Disponível em: <http://www.dizionario-italiano.it/>. Acesso em 23 de janeiro de 2009.

DRIP (2005). ALVES, A. T. Dicionário Rideel italiano-português-italiano. São Paulo: Rideel, 2005.

FARIAS, V. S. Dicionários escolares: análise e propostas de emendas. 2006. 102 f. Trabalho de Conclusão de Curso (Licenciatura em Letras) - Instituto de Letras, Universidade Federal do Rio Grande do Sul, Porto Alegre, 2006.

GDUEA (2001). Gran diccionario de uso del español actual. Madrid: SGEL, 2001.

HAENSCH, G. La lexicografía: de la lingüística teórica a la lexicografía práctica. Madrid: Gredos, 1982.

HARTMANN, R. R. K. Teaching and researching lexicography. London: Longman, 2001.

HARTMANN, R. R. K.; JAMES, G. Dictionary of lexicography. London: Routledge, 2001.

HouE (2001). HOUAISS, Antônio. Dicionário Houaiss da língua portuguesa. Rio de Janeiro: Objetiva, 2001. 1 CR-ROM.

KROMANN, Hans-Peder, RIIBER, Theis, ROSBACH, Poul. Principles of bilingual lexicography. In: HAUSMANN, F. J.; REICHMANN, O.; WIEGAND, H. E.; ZGUSTA, L. (Org.). Wörterbücher. Dictionaries. Dictionnaires. Ein Internationales Handbuch zur Lexikographie. V.3. Berlin: Walter de Grujter, 1991, p. 2711-2728.

LANDAU, S. Dictionaries: The art and craft of lexicography. Cambridge: Cambridge University Press, 2001.

LODUCA, $\quad$ M. $\quad$ G. La variabilità linguistica. Disponível em: $<$ http://www.univirtual.it/corsi/2002_I/lo_duca/download/05.pdf $>$. Acesso em 15 de janeiro de 2009. 
MARELLO, Carla. Les différents types de dictionnaires bilingues. In: BÉJOINT, Henri, THOIRON, Philippe. Les dictionnaires bilingues. Paris: Duculot, 1996, 31-52.

MARTÍNEZ DE SOUSA, J. Diccionario de lexicografía práctica. Barcelona: Bibliograf, 1995.

MiDEI (2003). POLITO, A. G. MICHAELIS: Dicionário Escolar Italiano: italianoportuguês/português-italiano. São Paulo: Melhoramentos, 2003.

NEUBERT, A. Fact and fiction of the bilingual dictionary. In: EuraLEX '90 Proceedings. Barcelona: Bibliograf, 1992, p. 29-42.

PASSWORD (1998). Password: English dictionary for speakers of portuguese. São Paulo: Martins Fontes, 1998.

QUADRO (2002). Quadro Comune Europeo di Rifferimento per le Lingue: apprendimento, insegnamento, vallutazione. Milano: La Nuova Italia-Oxford, 2002. Disponível em: $<$ http://www.italianoperlostudio.it/upload/documenti/quadro\%20captilo\%203\%20italiano.pdf>. Acesso em 20 de janeiro de 2009.

RICHARDS, Jack C.; PLATT, John; PLATT, Heidi. Longman Dictionary of Language Teaching \& Applied Linguistics. Edinburgh Gate: Longman, 1992.

RIVA, H. C.; XATARA, C. M. A linguagem idiomática organizada em pares dicotômicos. Araraquara: Alfa, v. 49, 2005, p. 111-123.

SWANEPOEL, P. Dictionary typologies: a pragmatic approach. In: STERKENBURG, Piet van (org.). A practical guide to lexicography. Amsterdam: John Benjamins, 2003, p. 45-69.

SZENDE, T. Problèmes d'équivalence dans les dicrionnaires bilingues. In: BÉJOINT, H.; THOIRON, P. (Org). Les dictionnaires bilingues. Paris: Duculot, 1996, p. 111-126.

WELKER, H. A. Dicionários: Uma pequena introdução à lexicografia. Brasília: Thesaurus, 2004.

WERNER, R.; CHUCHUY, C. Qué son los equivalentes en el diccionario bilingüe? In: GERD, Wotjak (Org.). Estudios de lexicología y metalexicografía del español actual. Tübingen: Max Nienayer, 1992, p. 99-107.

ZGUSTA, Ladislav. Manual of Lexicography. The Hague: Mouton, 1971.

[1] Este artigo foi originalmente apresentado em 2008/2 como requisito parcial para aprovação na disciplina “Tópicos de Lexicografia Bilíngue”, ministrada pelo Prof. Dr. Félix Bugueño Miranda no PPG-Letras / UFRGS.

[2] [a type of dictionary which relates the vocabularies of two languages together by means of translation equivalents].

[3]

[un dictionnaire dans lequel des expressions dans une langue (dite langue source ou de départ) sont traduites dans une autre (dite langue cible ou langue d'arrivée). Mais ce n'est pas seulement la présence de deux langues qui fait d'un dictionnaire un bilíngue, c'est la raison pour laquelle les deux langues sont mises en contact, c'est-à-dire la communication, par la traduction, entre deux communautés qui ne partagent pas la même langue].

[4] [to provide help to someone who understands one language but not the other].

5

[to be an aid to the translator either in decoding a foreign-language text to an equivalent text in the native language or encoding a native-language text as an equivalent text in the foreign language].

[6] [aptitude à servir les deux communautès linguistiques soit en tant que dictionnaire de version, soit en tant que dictionnaire de thème].

[7] A esse respeito, Carvalho (2001, p. 53) adverte que muitos dicionários, embora pareçam bidirecionais, não o são, já que as informações que contêm não são suficientes para auxiliar os falantes de cada uma das línguas em suas respectivas tarefas. Para Landau (2001, p. 9), os dicionários bidirecionais se comportam, na verdade, como dois dicionários distintos, posto que servem a dois propósitos e desempenham duas funções diferenciadas.

[8]

Sobre esse particular, ver Kromann; Riiber; Rosbach (1991), Carvalho (2001, p. 47-58), Welker (2004, p. 193-214) e Bugueño Miranda; Damin (2005).

[9] O conceito de macroestrutura é apresentado na seção 4 deste trabalho.

[10] De acordo com Haensch (1982, p. 461-463), Hartmann (2001, p. 64-65) e Hartmann; James (2001, s.v. microstructure), a microestrutura pode ser definida como o conjunto ordenado de todas as informações dentro do artigo léxico. Contidas na microestrutura estão as informações sobre a categoria gramatical, a separação silábica, a pronúncia, a etimologia, o conteúdo semântico da unidade léxica, etc. Em suma, são concernentes a esse componente questões relativas à fixação de um programa de informações e à organização interna do verbete. Em se tratando de dicionários bilíngues, pode-se dizer que a apresentação dos equivalentes é o aspecto microestrutural de maior relevância e complexidade. Acerca da problemática dos equivalentes, cf. Haensch (1982, p. 285-294), Kromann; Riiber; Rosbach (1991, p. 2717-2718), Werner; Chuchuy (1992), Szende (1996), Neubert (1990), Hartmann; James (2001, s.v. equivalence, equivalent) e Welker (2004, p. 
[11]

Kromann; Riiber; Rosbach (1991, p. 2720) afirmam que em um dicionário passivo as informações morfológicas e sintáticas devem se referir à palavra entrada, ao passo que em um dicionário ativo essas informações devem se referir aos equivalentes.

[12]

Sobre o problema do anisomorfismo linguístico, cf. Zgusta (1971, p. 294-297), Kromann; Riiber; Rosbach (1991, p. 2716-2718), Hartmann (1991, p. 2856-2858), Szende (1996) e Hartmann; James (2001, s.v. anisomorphism). [13]

A disciplina que possibilita se lidar diretamente com as questões inerentes ao anisomorfismo é a Linguística Contrastiva (LC), definida por Hartmann; James (2001, s.v. contrastive linguistics) como "a branch of Linguistics concerned with the parallel description of two (usually contemporary) languages or language varieties for a practical purpose, such as foreign-language teaching or translation". Através do cotejo entre duas línguas, a LC busca estabelecer uma taxonomia de contrastes linguísticos que permita prever as possíveis dificuldades a serem enfrentadas pelos aprendizes da língua estrangeira, de modo que se possam criar novos hábitos para evitar o erro (uso de um item linguístico, na escrita ou na fala, que para o falante nativo da língua estrangeira soa como uma demonstração de falha ou incompletude na aprendizagem dessa língua, segundo Richards; Platt; Platt (1992, s.v. error)). Em se tratando de línguas relativamente próximas como o português e o italiano - que apresentam semelhanças entre si nos campos lexical, morfológico, sintático e fonológico - a LC se mostra um meio bastante eficiente para prever em quais aspectos os aprendizes poderão ter problemas em função das semelhanças entre os dois sistemas.

[14] Segundo Kromann; Riiber; Rosbach (1991, p. 2713), a questão do usuário "involves consideration on the part of the lexicographer for the dictionary's target group, its needs and competence, and the types of user situations that occur". [15]

Os trabalhos de Damim (2005), Farias (2006) e Bugueño Miranda (2007b) são exemplos do esforço pelo estabelecimento de um perfil de usuário, com o objetivo de tornar o dicionário uma ferramenta eficaz para o consulente. Damin (2005) e Farias (2006) desenvolvem um perfil de usuário para o dicionário escolar partindo das necessidades específicas desse público para chegar a uma definição do tipo e da quantidade de informações que deve conter esse tipo de obra. Já Bugueño Miranda (2007b) trata da definição de um perfil de usuário para um dicionário monolíngue de espanhol para universitários brasileiros.

[16]

[the user aspect must be said to be one of the areas that really need to be examined in more detail - we need to know more about the way people use bilingual dictionaries, and especially about their linguistic competence in the areas of pronunciation, grammar, semantics, style and their general or specialized knowledge of the foreign language and its culture].

[171

[17] [rarely does a bilingual dictionary identify the user for whom it is intended].

[18]

Esse documento é fruto de um projeto de política linguística desenvolvido pelo Conselho da Europa com o objetivo de unificar as diretrizes para o ensino e aprendizagem de línguas no âmbito europeu.

[19]

Bugueño Miranda; Farias (2007, p. 138) defendem a necessidade de se proceder a uma definição macroestrutural quantitativa para evitar a tendência dos dicionários a arrolar grande quantidade de lemas de escassa ou nula utilidade para o consulente, provocando o que os autores denominam "inchaço macroesrutural".

[20]

Sobre essa questão, Zgusta (1971, p. 309) diz que "the selection of the prospective entry-words which will be included in the bilingual dictionary should be governed by the type of the dictionary, above all by its intention and purpose."

[21] [22]

[rarer words, proper names, all the allomorphs of words, conjugated forms exactly as they are found (...)].

GDUEA (2001), por exemplo, emprega esse critério para a seleção de sua nominata. Baseado no número de ocorrências das unidades léxicas no corpus Cumbre, GDUEA (2001) estabeleceu uma escala de indicação de frequência que vai de 1 a 5, e essa informação é fornecida ao consulente, que encontra um indicador de frequência diante de cada palavra-entrada. A ausência desse indicador significa que a palavra teve uma frequência não significativa. Nesse dicionário, portanto, o uso é quantitativamente marcado.

[23]

Nem sempre é fácil delimitar com precisão a diferença entre a variação no eixo diafásico e a variação no eixo diastrático. Em função disso, abordaremos esses dois aspectos conjuntamente.

[24]

Gostaríamos de salientar que, na falta de um corpus, valemo-nos do site de busca Google para efetuar nossas pesquisas quantitativas tendo em vista que tal corpus é bastante "democrático", ou seja, que nele podemos encontrar textos dos mais variados gêneros, sendo que a maioria deles reflete a língua efetivamente em uso. É certo que essa ferramenta possui algumas restrições de ordem técnica, porém ela se mostrou bastante satisfatória para a obtenção das informações que buscávamos: dados relativos á frequência de uso de determinadas unidades léxicas. Para maiores considerações acerca da internet como corpus, ver Riva; Xatara (2005, p. 114) e Berber Sardinha (2004, p. 45-50).

[25] Averiguamos também a frequência de uso de palavras de intervalos lemáticos das letras "L" e "S", mas em função do espaço não foi possível apresentar os resultados obtidos.

[26] Valemo-nos somente do número de páginas não repetidas, conforme informação do próprio buscador.

[27]

Hartmann; James (2001, s.v. back matter) definem o Back Matter como "those component parts of a dictionary which are located between the central word-list section and the end of the work".

[28]

O Front Matter é constituído pelas partes introdutórias do dicionário e tem como principal função orientar os consulentes quanto às informações incluídas nos componentes macro-, micro- e medioestrutural (cf. Hartmann; James (2001, s.v. front matter).

[29]

Hartmann; James (2001, s.v. back matter) definem o Back Matter como "aquelas partes componentes de um dicionário que estão localizadas entre a macroestrutura e o fim da obra" [those component parts of a dictionary which are located between the central word-list section and the end of the work].

[30]

Com relação à aplicação dos conceitos de type e token à análise de dicionários de língua, cf. Bugueño Miranda (2005 e 2007a). 
[31] No caso específico desses vocábulos, dado que encontramos um número de ocorrências expressivo, seríamos partidários de que fossem lematizados, porém fornecendo ao consulente a informação de que são formas arcaicas.

[32] Os dicionários de língua inglesa adotam essa postura, lematizando formas token, tais como swum "past participle of swim", kept "past tense and past participle of keep" (cf. CELD (2004, s.v.)), thought "see think" (cf. PASSWORD (1998, s.v.)).

[33]

Acreditamos que esse recurso poderia ser mais bem aproveitado se o dicionário, em cada forma verbal lematizada, remetesse o consulente ao modelo de conjugação. Dessa forma o aprendiz teria à disposição um conjunto de informações que certamente seria útil para o desenvolvimento de seus conhecimentos da língua estrangeira. 